\title{
ANALISIS TINGKAT KEBISINGAN DAN USAHA PENGENDALIAN PADA UNIT PRODUKSI PADA SUATU INDUSTRI DI KOTA BATAM
}

\author{
Vera Surtia Bachtiar ${ }^{1)}$, Yommi Dewilda ${ }^{2)}$ dan BerlindaVaniake Wemas ${ }^{1)}$ \\ ${ }^{1)}$ Laboratorium Kualitas Udara Jurusan Teknik Lingkungan Universitas Andalas \\ ${ }^{2)}$ Laboratorium Buangan Padat Jurusan Teknik Lingkungan Universitas Andalas \\ Email: vera_sb@ft.unand.ac.id
}

\begin{abstract}
ABSTRAK
Analisis tingkat kebisingan dilakukan pada suatu unit produksi Fusion Bonded Epoxy (FBE), Industri $X$ yang berada di Kota Batam. Penelitian dilakukan pada 45 titik pengukuran. Tujuan penelitian ini adalah untuk mengetahui intensitas kebisingan yang dihasilkan oleh unit produksi Industri X. Metode pengukuran tingkat tekanan suara mengacu pada KepMenLH No 48 Tahun 1996, dan alat yang digunakan adalah Sound Level Meter. Pengukuran tingkat tekanan suara (Lp) dilakukan selama 1 shift kerja. Hal ini dikarenakan berdasarkan penelitian pendahuluan diperoleh nilai tingkat tekanan suara ekivalen (Leq) 24 jam adalah sama. Intensitas kebisingan tertinggi dihasilkan pada lokasi coupling insertion yaitu sebesar $92 d B(A)$, dan intensitas kebisingan terendah terdapat pada area di dekat kantin yaitu sebesar $62 d B(A)$. Berdasarkan hasil evaluasi kebisingan, 12 titik pengukuran (26,7 $\%)$ telah melebihi Nilai Ambang Batas (NAB) kebisingan menurut KepMenaker No 51/1999 (85 dB(A) untuk 8 jam kerja perhari). Upaya pengendalian kebisingan yang direncanakan adalah dengan pemasangan vibration isolation, partial enclosure, muffler, pengendalian secara administrasi dan pengendalian bising pada pekerja (pemakaian earplug dan earmuff)
\end{abstract}

Kata kunci: Industri X, kebisingan, tingkat tekanan suara, pengendalian kebisingan.

\begin{abstract}
Analysis of Noise level was conducted in a production unit, unit produksi Fusion Bonded Epoxy $(F B E)$, Industry $X$ in the city of Batam. The study was conducted at 45 measuring points. The purpose of this study was to determine the intensity of the noise generated by production unit in Industry $X$. Method of measuring the sound pressure level refers to KepMenLH No. 48 of 1996, using a Sound Level Meter. Measurement of sound pressure level ( Lp ) was done just for 1 shift of work, because in preliminary research obtained value equivalent sound pressure level ( Leq) is similar with 24 hours. Highest intensity of noise generated in the coupling insertion location is equal to $92 \mathrm{~dB}(\mathrm{~A})$, and the lowest noise intensity found in the area near the cafeteria is equal to $62 \mathrm{~dB}(A)$. Based on the evaluation of noise , 12 measurement points ( $26.7 \%$ ) have exceeded the threshold limit value (TLV) noise according to KepMenaker No. $51 / 1999$ (85 dB(A) for 8 hours per day). Recomendation for noise control is the installation of vibration isolation, partial enclosure, muffler, control the administration and control of noise on workers (use earplug and earmuff )
\end{abstract}

Keywords: Industry X, noise, sound pressure level, noise control. 


\section{PENDAHULUAN}

Industri $\mathrm{X}$ terletak di Kawasan Industri Terpadu Kabil, Batam, Kepulauan Riau. Industri ini adalah salah satu perusahaan yang bergerak dalam bidang pelapisan pipa baja (pipe coating). Dalam pelaksanaan operasinya Industri $\mathrm{X}$ banyak menggunakan mesin-mesin dan peralatan yang menimbulkan intensitas kebisingan yang tinggi seperti blasting machine, induction coil, coating spray gun, extruder, quenching, grinding dan lainnya, sehingga dikhawatirkan akan berpengaruh terhadap pekerja yang bekerja pada unit-unit produksi di Industri X.

Oleh karena itu, untuk mengetahui keadaan dan pola penyebaran kebisingan yang lebih mendalam, perlu dilakukan penelitian mengenai sumber, tingkat kebisingan, pola penyebaran dan pemetaan kebisingan di Industri $\mathrm{X}$ khususnya pada unit produksi FBE.

Berdasarkan KepMenakertrans No 13 tahun 2011, kebisingan adalah suara yang tidak dikehendaki yang bersumber dari alat dan proses produksi yang pada tingkat tertentu dapat menimbulkan gangguan pendengaran.

Definisi resmi mengenai kebisingan tercantum di dalam Keputusan Menteri Negara Lingkungan Hidup Republik Indonesia Nomor 48/MenLH/Tahun 1996, yaitu bising adalah bunyi yang tidak diinginkan dari suatu usaha atau kegiatan dalam tingkat waktu tertentu yang dapat menimbulkan gangguan kesehatan dan kenyamanan lingkungan. KepMenLH No.48 tahun 1996 tersebut juga merupakan standar baku mutu tingkat kebisingan lingkungan yang berlaku di Indonesia. Bagi kawasan Industri atau pabrik, nilai ambang batas kebisingan diatur melalui
Surat Keputusan KepMenakertrans No 13 tahun 2011 tentang ambang batas kebisingan maksimum sebesar $85 \mathrm{~dB}(\mathrm{~A})$ untuk 8 jam kerja perhari.

Energi ekivalen merupakan nilai tertentu dari pengukuran kebisingan yang berubahubah atau befluktuasi selama waktu tertentu yang setara dengan tingkat kebisingan dari kebisingan yang steady pada selang waktu yang sama (Kep. Men LH No 48, 1996).

Bila hasil pengukuran mempunyai data yang terdistribusi normal, maka untuk menghitung nilai Leq digunakan rumus sebagai berikut:

$$
\text { Leq }=L_{50}+\frac{\left(L_{10}-L_{90}\right)^{2}}{60} \ldots \ldots \ldots \ldots \ldots 1
$$

Dimana :

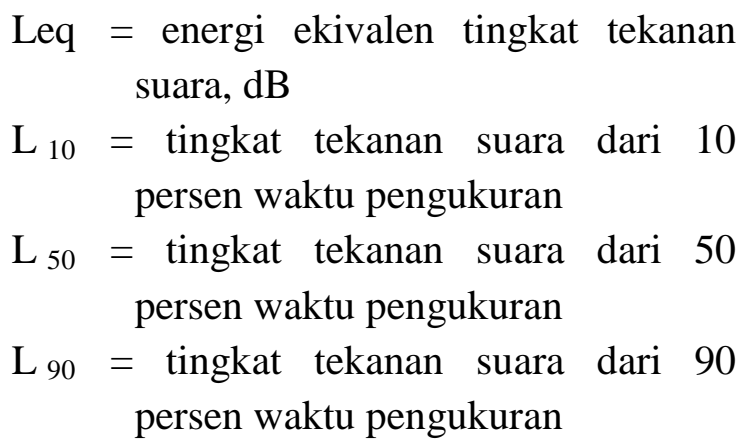

\section{Hubungan Intensitas Kebisingan dengan Tingkat Kesulitan Kerja}

Hubungan antara faktor kebisingan dan faktor tingkat kesulitan kerja terhadap produktivitas diantaranya dapat terlihat, yaitu efek dari kebisingan secara fisiologis terbukti dapat mempengaruhi konsentrasi secara mental, meningkatkan tekanan darah, mempercepat denyut jantung, dapat menutup pembuluh darah pada kulit, meningkatkan metabolisme, menyebabkan gangguan pencernaan, serta meningkatkan ketegangan pada otot (Hidayah, 2009).

Pengaruh kebisingan intensitas tinggi (di atas NAB) adalah dapat menyebabkan stress pada karyawan yang secara spesifik 
dapat mengakibatkan stres menuju keadaan cepat marah, sakit kepala, gangguan tidur, gangguan reaksi psikomotor, kehilangan konsentrasi, gangguan komunikasi antar lawan bicara dan penurunan performansi kerja yang kesemuanya itu akan bermuara pada kehilangan efisiensi dan produktivitas kerja (Tarwaka, 2004). Selain itu Kebisingan mempunyai efek merugikan kepada daya kerja, yaitu mengganggu komunikasi pembicaraan. Kebisingan dapat mengganggu perhatian dan konsentrasi yang dicurahkan kepada pekerjaan. Kelelahan dalam melakukan pekerjaan dapat menyebabkan terjadinya defisiensi performa kerja dan dapat menyebabkan terjadinya penurunan produktifitas tenaga kerja (Setyorini, 2010).

\section{Standar Nilai Ambang Batas Kebisingan}

Nilai ambang batas kebisingan (NAB) adalah intensitas kebisingan tertinggi dan merupakan nilai rata-rata yang masih dapat diterima oleh manusia tanpa mengakibatkan hilangnya daya dengar yang tetap untuk waktu yang cukup lama atau terus menerus. Penting untuk diketahui bahwa di dalam menetapkan standar NAB pada suatu level atau intensitas tertentu, tidak akan menjamin bahwa semua orang yang terpapar pada level tersebut secara terus menerus akan terbebas dari gangguan pendengaran, karena hal itu tergantung pada respon masing-masing individu (KepMenLH No 48, 1996).

Pada lingkungan kerja Industri, tingkat kebisingan yang dihasilkan biasanya cukup tinggi sehingga harus ada batas waktu pajanan kebisingan. Batasan kebisingan yang ditetapkan oleh The Workplace and Safety Noise Compliance Standard, SL No
381 adalah 8 jam terus menerus pada level tekanan suara $85 \mathrm{~dB}(\mathrm{~A})$, dengan referensi 20 micropascal (NIOSH, 1998).

\section{Gambaran Umum Wilayah Studi}

Industri $\mathrm{X}$ merupakan perusahaan yang bergerak di bidang pelapisan pipa baja (pipe coating) dan banyak menunjang perindustrian minyak bumi dan gas dalam hal penyediaan pipa baja bagi industri minyak bumi dan gas.

Kawasan Industri X mempunyai luas total sebesar $580.000 \mathrm{~m}^{2}$ atau sekitar 58 hektar yang dilengkapi oleh berbagai sarana dan fasilitas, serta terdiri dari beberapa unit produksi, salah satunya adalah unit produksi FBE (Fusion Bonded Epoxy). Unit produksi FBE merupakan salah satu unit produksi (plant) yang terdapat pada Industri $X$ yang memiliki intensitas kebisingan yang tinggi dibandingkan dengan unit produksi lainnya yang terdapat di Industri $X$.

\section{METODOLOGI PENELITIAN}

Pada penelitian ini dilakukan survei pendahuluan untuk mengamati apakah kawasan layak dijadikan daerah studi, selain itu identifikasi kawasan bertujuan untuk mengetahui sumber-sumber kebisingan pada daerah studi. Identifikasi kawasan dilakukan dengan cara melihat langsung daerah yang akan dijadikan daerah studi. Identifikasi kawasan juga bertujuan untuk mengetahui sumbersumber kebisingan yang dihasilkan dari aktifitas produksi.

Dalam penelitian ini dilakukan pengumpulan data sekunder dan data primer. Data sekunder yang diperlukan sebagai data pendukung diperoleh dari pihak manajemen Industri $\mathrm{X}$. Data 
sekunder yang diperlukan untuk menunjang penelitian ini meliputi peta lokasi, gambaran umum Industri X.

Selain itu dilakukan penentuan koordinat dan titik pengukuran dengan menggunakan alat Global Positioning System (GPS) dan meteran, kemudian memberikan patok pada titik-titik pengukuran. Lokasi pengukuran tingkat kebisingan adalah pada unit produksi FBE (Fusion Bonded Epoxy), Industri $\mathrm{X}$.

Pengukuran tingkat kebisingan yang dilakukan hanya 1 kali pada masingmasing titik pengukuran. Pengukuran tingkat tekanan suara selama sekali pengukuran mengacu pada KepMenLH No 48 Tahun 1996, yaitu pengukuran tingkat tekanan suara pada setiap titik dilakukan selama 10 menit dan pembacaan dilakukan setiap 5 detik. Pengukuran ini dilakukan secara berkelanjutan dari satu titik ke titik lain dengan asumsi tingkat kebisingan yang dihasilkan oleh unit produksi FBE hampir sama setiap waktunya mengingat proses produksi yang dilaksanakan tidak berbeda.

Selain data sekunder, dilakukan pengukuran data primer. Data primer diperoleh dari hasil pengukuran langsung di lapangan. Pengukuran di lapangan dilakukan berdasarkan hari dan waktu yang telah ditetapkan. Data primer yang diukur pada masing-masing titik pengukuran adalah tingkat tekanan suara (Lp). Pengukuran tingkat tekanan suara ini meliputi dua kegiatan berikut:

a. Pengukuran kondisi meteorologi

b. Pengukuran tingkat tekanan suara (Lp)

Langkah selanjutnya adalah analisis data dan pembahasan, yang terdiri atas: a. Analisis tingkat kebisingan

b. Membandingkan hasil pengukuran tingkat tekanan suara dengan standar baku mutu yang digunakan untuk daerah industri yang mengacu pada KepMenakertrans No 13 tahun 2011 tentang Nilai Ambang Batas Faktor Fisika di Tempat Kerja

c. Upaya pengendalian kebisingan

\section{HASIL DAN PEMBAHASAN Pengukuran Tingkat Tekanan Suara}

Pengukuran tingkat tekanan suara dilakukan pada saat pabrik beroperasi dengan normal, sehingga dapat terukur besar intensitas tekanan suara yang dihasilkan oleh mesin-mesin produksi. Pengukuran tingkat tekanan suara ini meliputi dua kegiatan, yaitu pengukuran kondisi meteorologi dan pengukuran intensitas tekanan suara (Lp) pada lokasi sampling.

\section{Hasil Pengukuran Kondisi Meteorologi}

Pengukuran kondisi meteorologi merupakan faktor penting dalam melakukan pengukuran tingkat tekanan suara. Kondisi meteorologi seperti suhu, kelembaban, tekanan udara, arah dan kecepatan angin dapat berpengaruh terhadap besarnya intensitas suara yang terukur.

a. Suhu

Suhu udara pada saat melakukan pengukuran pada titik sampling berkisar antara $26,3-33,8^{0} \mathrm{C}$ dan $23,0-34,4^{0} \mathrm{C}$. Suhu udara yang terukur pada saat sampling dilakukan tidak berpengaruh terhadap tingkat tekanan suara yang terbaca pada Sound Level Meter (SLM). Hal ini dikarenakan SLM dibuat untuk bekerja pada range suhu antara $-10^{\circ} \mathrm{C}$ hingga $50^{\circ} \mathrm{C}$ $\left(14-122^{0} \mathrm{~F}\right)$ (SNI No 7231, 2009). 


\section{b. Kelembaban udara}

Sound Level Meter tidak akan dipengaruhi oleh kelembaban nisbi sampai tingkat 90 $\%$ (SNI No 7231, 2009). Dari data meteorologi yang terukur di titik sampling, tingkat kelembaban udara yang terukur berkisar antara 48,1-60,3\% dan 46,7$68,7 \%$ sehingga kelembaban udara tidak berpengaruh terhadap pengukuran tingkat tekanan suara.

c. Tekanan udara

Tekanan udara saat dilakukan sampling adalah sebesar 25,59-29,98 inHg. Kondisi tekanan udara seperti ini tidak berpengaruh terhadap pengukuran tingkat tekanan suara pada titik sampling. Hal ini dikarenakan perubahan tekanan atmosfer sampai $10 \%$ masih dapat diabaikan terhadap kepekaan mikrofon Sound Level Meter (SNI No 7231, 2009).

\section{d. Kecepatan Angin}

Kecepatan angin pada saat pengukuran dilakukan adalah sebesar 0,2-1,1 m/s Pada kondisi ini, kecepatan angin pada saat pengukuran tidak melebihi $5 \mathrm{~m} / \mathrm{s}$ sehingga tidak berpengaruh terhadap perubahan tingkat tekanan suara yang terukur pada alat Sound Level Meter (PerMenLH No 07, 2009).

\section{e. Arah angin}

Pada kondisi angin bertiup dari sumber bunyi menuju suatu titik, maka titik tersebut akan menerima bunyi lebih cepat. Sebaliknya, angin yang bertiup menuju arah yang berlawanan maka titik tersebut akan menerima kekuatan yang lebih lemah. Pada saat pengukuran, kecenderungan arah angin bertiup adalah ke arah timur.

\section{Hasil Pengukuran Tingkat Tekanan Suara $(\mathbf{L p})$}

Pengukuran tingkat tekanan suara (Lp) dilakukan untuk mengetahui tingkat tekanan suara yang dihasilkan dari sumber bising.

Hasil Pengukuran tingkat tekanan suara pada 45 titik pengukuran dapat dilihat pada Gambar 1.

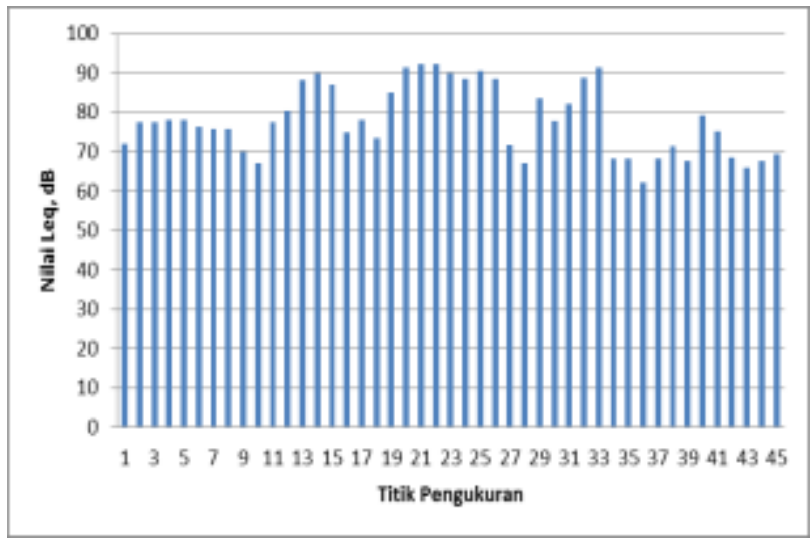

Gambar 1. Nilai Leq

Titik dengan kebisingan tertinggi berada pada titik 21 (area coupling insertion) sebesar $92 \mathrm{~dB}(\mathrm{~A})$. Tingkat kebisingan terendah berada pada titik 36 (di dekat kantin) yaitu sebesar $62 \mathrm{~dB}(\mathrm{~A})$.

\section{Analisis Tingkat Kebisingan}

Berdasarkan hasil perhitungan nilai Leq, maka dilakukan analisis pola penyebaran tingkat kebisingan. Analisis ini digunakan untuk menggambarkan pola penyebaran kebisingan yang diterima oleh pekerja.

Pada unit produksi FBE, tingkat kebisingan yang dihasilkan sangat tinggi. Seluruh area yang berada di dalam unit produksi FBE merupakan lokasi yang memiliki intensitas kebisingan yang sangat tinggi, sedangkan area di sekitar unit produksi masih termasuk dalam wilayah aman. Akan tetapi, untuk tingkat kebisingan pada titik pengukuran yang berada dekat dengan dinding bangunan unit produksi FBE bisa saja mengalami pengurangan tingkat kebisingan. Hal ini dikarenakan adanya penyerapan (insulasi) bunyi oleh dinding bangunan. Oleh karena itu, pengukuran kebisingan pada titik yang dekat dengan dinding harus dilakukan 
sejauh 3 meter dari dinding untuk menghindari adanya insulasi bunyi oleh dinding bangunan.

Analisis kebisingan berguna untuk mengetahui lokasi dimana pekerja diwajibkan menggunakan alat pelindung pendengaran (hearing protective equipment). Peta isodesibel tingkat kebisingan unit produksi FBE (Fusion Bonded Epoxy), Industri $\mathrm{X}$ dapat dilihat pada Gambar 2. Pada area dengan tingkat kebisingan 80-85 dB(A), (zona warna kuning) pekerja tidak diwajibkan menggunakan alat pelindung pendengaran.
Pada area ini tingkat kebisingan yang dihasilkan oleh sumber bising masih berada di dalam batas aman ambang batas kebisingan menurut KepMenakertrans No 13 tahun 2011 yaitu sebesar $85 \mathrm{~dB}(\mathrm{~A})$ untuk 8 jam kerja perhari. Tetapi pada zona ini pekerja disarankan untuk memakai alat pelindung pendengaran berupa earplug untuk menghindari timbulnya Penyakit Akibat Kerja (PAK) akibat paparan kebisingan yang terusmenerus. untuk titik sampling 19 berturutturut adalah $83 \mathrm{~dB}(\mathrm{~A}), 81 \mathrm{~dB}(\mathrm{~A})$ dan 83 $\mathrm{dB}(\mathrm{A})$.

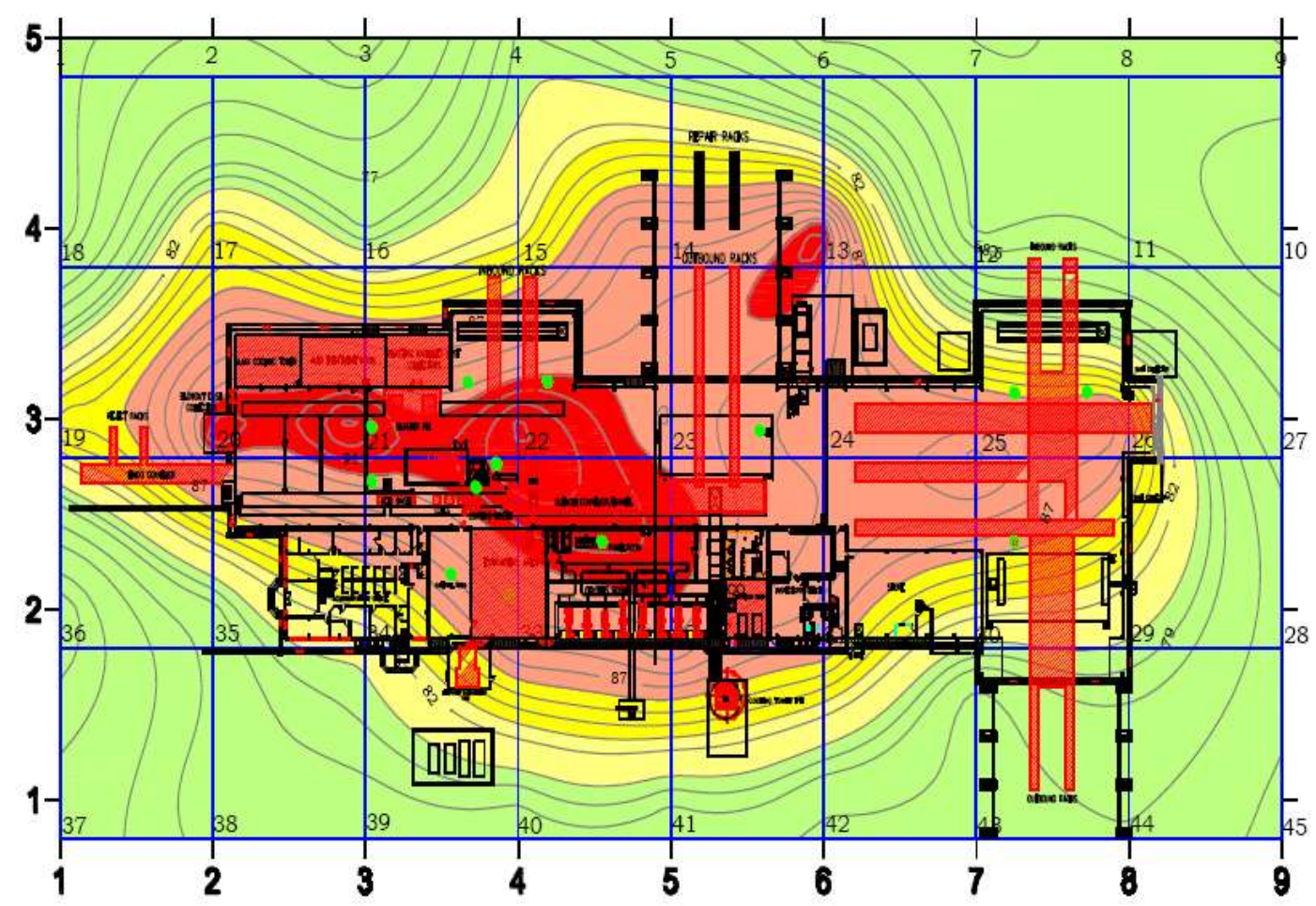

Gambar 2. Peta isodesibel tingkat kebisingan unit produksi FBE (Fusion Bonded Epoxy), Industri X 


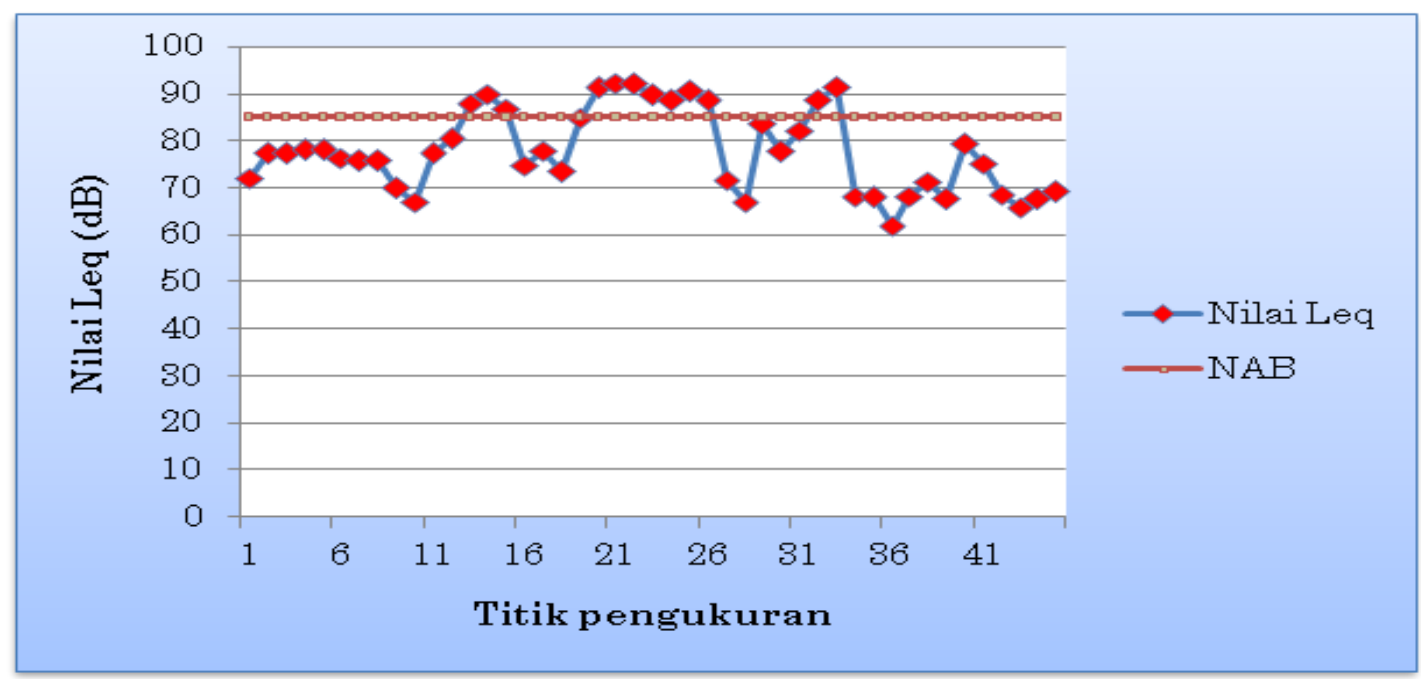

Gambar 3. Perbandingan nilai Leq dengan nilai ambang batas kebisingan (NAB)

Zona dengan intensitas 85-90 dB(A), (zona warna merah muda) merupakan zona dimana pekerja diwajibkan untuk menggunakan earplug. Pada zona di atas $90 \mathrm{~dB}(\mathrm{~A})$ (zone warna merah), pekerja diwajibkan untuk menggunakan earmuff yang mempunyai nilai NRR (Noise Reduce Rate) yang lebih besar dibandingkan dengan earplug.

Berdasarkan KepMenakertrans No 13 tahun 2011 yaitu sebesar $85 \mathrm{~dB}(\mathrm{~A})$ untuk 8 jam kerja per hari, terdapat 12 titik pengukuran yang berada di atas nilai ambang batas kebisingan, sepeti terlihat pada Gambar 3.

\section{Upaya Pengendaliuan Tingkat Kebisingan}

Berdasarkan hasil pengukuran intensitas kebisingan, diperoleh hasil bahwa tingkat kebisingan pada lingkungan kerja unit produksi FBE telah melewati baku mutu menurut KepMenakertrans No 13 tahun 2011 tentang Nilai Ambang Batas Faktor Fisika di Tempat Kerja yaitu sebesar 85 $\mathrm{dB}(\mathrm{A})$ untuk 8 jam kerja per hari. Upaya pengendalian bising yang dapat dilakukan dapat meliputi pengendalian secara teknik, pengendalian bising secara administratif dan pengendalian bising pada penerima.

Pengendalian secara teknik meliputi pemasangan vibration isolation, pemasangan vartial enclosure, dan pemasangan muffler.

Bentuk pengendalian bising secara administrasi yang dapat dilakukan adalah melakukan rotasi kerja bagi karyawan yang mengeluhkan adanya gangguan pendengaran. Rotasi kerja dapat dilakukan dengan cara memindahkan karyawan tersebut ke unit produksi lain yang memiliki tingkat kebisingan rendah. Hal ini dimaksudkan agar perubahan ambang pendengaran dapat bersifat sementara dan fungsi pendengaran karyawan dapat kembali seperti semula apabila karyawan tersebut dijauhkan dari kebisingan untuk sementara waktu.

Pengendalian bising pada penerima dilakukan sebagai upaya pengendalian terakhir, yaitu dengan cara mereduksi tingkat kebisingan yang diterima oleh pekerja dengan menggunakan alat pelindung pendengaran berupa earplug maupun earmuff.

Tabel 1 berikut memperlihatkan pengurangan atau reduksi suara setelah 
dilakukannya upaya pengendalian kebisingan berupa pemasangan vibration isolation, pemasangan partial enclosure, pemasangan muffler, pemakaian earplug, dan earmuff.

\section{SIMPULAN}

Tingkat kebisingan tertinggi berada pada titik 21 (area coupling insertion) yaitu sebesar $92 \mathrm{~dB}(\mathrm{~A})$, dan tingkat kebisingan terendah terdapat pada titik 36 yaitu pada area disekitar kantin, yaitu sebesar 62 $\mathrm{dB}(\mathrm{A})$.

Terdapat 12 titik pengukuran pada unit produksi FBE yang telah melewati Nilai Ambang Batas (NAB) kebisingan berdasarkan KepMenaker Nomor 51/Tahun 1999 yaitu sebesar 85 dB untuk 8 jam waktu kerja. Jadi, sebesar 26,7 \% titik telah melebihi standar tingkat kebisingan.

Alternatif pengendalian bising yang dapat dilakukan meliputi pengendalian bising secara teknik (pemasangan vibration isolation, partial enclosure dan muffler), pengendalian secara administrasi dan pengendalian bising pada pekerja (menggunakan earplug dan earmuff).

\section{DAFTAR PUSTAKA}

Hidayah, N. Y. 2009. Analisis Pengaruh Faktor Kebisingan dan Tingkat Kesulitan Kerja terhadap Produktifitas Line Assembling PT $X$. Universitas Pancasila:Jakarta.

Keputusan Menteri Negara Lingkungan Hidup No 48 Tahun 1996. Baku Tingkat Kebisingan.

Keputusan Menteri Tenaga Kerja dan Transmigrasi No 51 Tahun 1999. Nilai Ambang Batas Faktor Fisika di Tempat Kerja.

National Institute for Occupational Safety and Health (NIOSH). 1998. Occupational Noise Exposure, Cincinnati-Usa.

PerMenLH No. 07 Tahun 2009. Ambang Batas Kebisingan Kendaraan Bermotor Tipe Baru

Setyorini, R. 2010. Gambaran Kebisingan Area Amonia dan Pengaruhnya terhadap Tenaga Kerja di PT Pupuk Kujang Cikampek. Universitas Sebelas Maret: Surakarta.

Standar Nasional Indonesia No 7231. 2009. Metode Pengukuran Intensitas Kebisingan di Tempat Kerja. Badan Standarisasi Nasional.

Tarwaka. 2004. Keselamatan dan Kesehatan Kerja Mangemen dan Implementasi K3 di Tempat Kerja. Harapan Press: Surakarta. 
Tabel 1. Pengurangan Tingkat Kebisingan setelah Penggunaan Alat Pereduksi Kebisingan pada unit produksi FBE (Fusion Bonded Epoxy), Industri X.

\begin{tabular}{|c|c|c|c|c|}
\hline $\begin{array}{c}\text { Titik } \\
\text { Sampling }\end{array}$ & Lokasi & $\begin{array}{c}\text { Upaya } \\
\text { Pengendalian } \\
\end{array}$ & $\begin{array}{l}\text { Tingkat Bising } \\
\text { Awal }(\mathrm{dB}(\mathrm{A}))\end{array}$ & $\begin{array}{c}\text { Tingkat Reduksi } \\
\text { Suara }(\mathrm{dB}(\mathrm{A}))\end{array}$ \\
\hline 13 & Boiler unit produksi FBE & earplug+earmuff & 88 & 24 \\
\hline 14 & Outgoing racks unit produksi FBE & earplug+earmuff & 90 & 24 \\
\hline 15 & Inbound racks unit produksi FBE & earplug+earmuff & 87 & 24 \\
\hline 20 & $\begin{array}{l}\text { Blow dust collector unit produksi } \\
\text { FBE }\end{array}$ & earplug+earmuff & 91 & 24 \\
\hline 21 & $\begin{array}{l}\text { Area coupling insertion unit produksi } \\
\text { FBE }\end{array}$ & $\begin{array}{c}\text { Vibration } \\
\text { isolation+earplug } \\
+ \text { earmuff }\end{array}$ & 92 & $10+24$ \\
\hline 22 & $\begin{array}{l}\text { Depan hot water system unit produksi } \\
\text { FBE }\end{array}$ & muffler & 92 & 30 \\
\hline 23 & $\begin{array}{l}\text { Sekitar area thickness test unit } \\
\text { produksi FBE }\end{array}$ & earplug+earmuff & 90 & 24 \\
\hline 24 & $\begin{array}{l}\text { Dekat hydraulic system unit produksi } \\
\text { FBE }\end{array}$ & earplug+earmuff & 89 & 24 \\
\hline 25 & Dekat mesin blaster Plant Internal & $\begin{array}{c}\text { partial enclosure+ } \\
\text { earplug }\end{array}$ & 90 & $20+8,5$ \\
\hline 26 & Dekat inbound racks Plant Internal & earplug + earmuff & 89 & 24 \\
\hline 32 & $\begin{array}{l}\text { Belakang compressor room unit } \\
\text { produksi FBE }\end{array}$ & muffler & 89 & 30 \\
\hline 33 & $\begin{array}{l}\text { Sekitar extruder area unit produksi } \\
\text { FBE }\end{array}$ & earplug+earmuff & 91 & 24 \\
\hline
\end{tabular}

